\title{
HIGH-PRECISION RADIOCARBON DATING OF BRISTLECONE PINE FROM 6554 TO 5350 BC
}

\author{
TIMOTHY W LINICK, AUSTIN LONG, PAUL E DAMON, and C WESLEY FERGUSON $†$
}

Department of Geosciences, University of Arizona, Tucson, Arizona 85721

ABSTRACT. New results of radiocarbon dating of ca 100 decadal bristlecone pine samples from $6554 \mathrm{BC}$ to $6084 \mathrm{BC}$ and from 5820 to $5350 \mathrm{BC}$ are presented. Using 3 new $2.5 \mathrm{~L}$ counters filled to ca 3atm with carbon dioxide, high-precision dating has been performed by this laboratory for more than two years. Demonstration of the precision and accuracy of these counters is presented using $\pm 2 \%$ measurements from the Sporer minimum period. For the older samples, $\pm 3 \% 0$ measurements were made using ca 12-day counting times. Results are presented both as ${ }^{4} \mathrm{C}$ age BP $v s$ dendro-year $\mathrm{BC}$, particularly for calibration purposes, and as $\Delta^{14} \mathrm{C} v s$ time.

\section{INTRODUCTION}

Radiocarbon analysis of bristlecone pine tree rings of known age has been one of the primary projects of the University of Arizona's conventional radiocarbon lab for many years (Damon, Long \& Grey, 1966; Damon, Long \& Wallick, 1972; Damon, Lerman \& Long, 1978; Klein et al, 1980). Similar work was in progress at the La Jolla radiocarbon lab (eg, see Suess, 1970, 1978, 1980; Bruns et al, 1983; Linick, Suess \& Becker, 1985) until the cessation of the operation of that lab in 1982. The purpose of this work is two-fold: 1) to provide a calibration of the ${ }^{14} \mathrm{C}$ time scale for the conversion of ages in ${ }^{14} \mathrm{C}$ years BP to ranges of true calendar years; 2) to study the variations of atmospheric ${ }^{14} \mathrm{C}$ levels with time as a matter of geophysical interest to examine the causes of these secular variations, ie, changes in the strength of the earth's magnetic field and changes in the flux of solar and cosmic rays.

In 1979, new 2.5L copper counters using the design of Minze Stuiver (Stuiver, Robinson \& Yang, 1979) were built and installed in our shield to enable high-precision analysis $\left(\sigma_{\Delta^{14} \mathrm{C}} \leq 3 \%\right.$ ) of the ${ }^{14} \mathrm{C}$ concentration in tree rings of known age. There are 3 of these counters, 3 smaller gas counters, and a liquid scintillation counter in the lab now; nearly 4000 samples have been measured with them.

CELLULOSE EXTRACTION PROCEDURE

In order to isolate the most reliable, least mobile fraction of the wood, it is our practice to extract the holocellulose from the $40 \mathrm{~g}$ bristlecone pine samples received from the Laboratory of Tree-Ring Research at our institution. The decadal wood samples are cut into matchstick-sized pieces and are then ground to 20 mesh size in a Wiley mill. The chemical pretreatment starts with resin extraction. Using a Soxhlet apparatus, the sample is treated for ca 20 hours with a solvent mixture consisting of $250 \mathrm{ml}$ of toluene and $125 \mathrm{ml}$ of $100 \%$ ethanol heated to ca $170^{\circ} \mathrm{C}$. The next day, the apparatus is allowed to cool, and the sample is air-dried. The sample is treated with $350 \mathrm{ml} 100 \%$ ethanol for another 20 hours, using the Soxhlet device. The next day, the apparatus is again allowed to cool, and the sample is again air-dried. The sample is rinsed for several hours with warm distilled water in a beaker. To perform the actual cellulose extraction, the sample is placed in a beaker and covered with distilled water to which 15 drops of glacial acetic

† Deceased March 24, 1986. acid and ca $5 \mathrm{ml}$ volume of sodium chlorite (technical or reagent grade) is added. This solution is heated to $70^{\circ} \mathrm{C}$. This bleaching procedure is repeated every 2 to 3 hours until the sample is white. The sample/solution mixture is allowed to sit overnight; if the sample is not yet white, the bleaching procedure is repeated. After the wood has been satisfactorily bleached, it is rinsed with distilled water repeatedly, until one cannot smell the acetic acid, the solution is clear, and the sample is white. The sample is then dried in an oven at ca $110^{\circ} \mathrm{C}$ until completely dry.

CARBON DIOXIDE SAMPLE PREPARATION PROCEDURE

Combustion of the cellulose is performed in a high-pressure combustion bomb. Ca $11 \mathrm{~g}$ of the cellulose is pressed into a pellet which is placed in the combustion bomb with an ignition wire embedded into the pellet. A small tray of potassium permanganate solution is placed inside of the bomb. The bomb is then sealed, evacuated, and pressurized with oxygen. After electrically igniting the sample, the resulting carbon dioxide, oxygen, water vapor gas mixture is slowly bled through the gas purification system. This system, modeled after that of Roy Switsur (pers commun), consists of a trap immersed in dry ice/ethanol slush, a trap containing silver powder heated to $250^{\circ} \mathrm{C}$, a trap containing cupric oxide heated to $700^{\circ} \mathrm{C}$, a trap containing vanadia catalyst heated to $500^{\circ} \mathrm{C}$ (to convert $\mathrm{SO}_{2}$ to $\mathrm{SO}_{3}$ ), and a long tubing pathway trap immersed in dry ice slush to trap out sulfur oxides and water. The carbon dioxide is then isolated in a trap immersed in liquid nitrogen, with the excess oxygen pumped off at a rate fast enough to maintain a pressure low enough to avoid condensation of oxygen in the trap. When the entire gaseous contents of the bomb have been passed through this system, a procedure taking a few hours, the carbon dioxide is pumped to high vacuum. The carbon dioxide is then allowed to sublime slowly, passing through phosphorus pentoxide powder to complete the drying, and then frozen into a cold finger located on the final purification apparatus; after again pumping the sample to high vacuum, the carbon dioxide is then allowed to expand into a large volume convective recirculation tower with elemental copper turnings heated to $475^{\circ} \mathrm{C}$ to remove remaining traces of oxygen, a system modeled after that of Minze Stuiver. After remaining in the glass tower for at least 6 days, the sample is frozen into a stainless steel cylinder for storage. To allow for decay of ${ }^{222} \mathrm{Rn}$, the sample remains in its cylinder for a minimum of 30 days before counting, a length of time found to be sufficient for these cellulose samples.

\section{COUNTING PRACTICES}

The three $2.5 \mathrm{~L}$ counters are filled to a pressure of $45 \mathrm{psi}$ at a shield temperature of $30^{\circ} \mathrm{C}$. The counters are very stable, and all three have very similar counting characteristics. The anti-coincidence circuit used here 
includes individual proportional counter tubes lining the inside of the iron shield, with two layers of such tubes on the top; in addition, the six gas counters are themselves included in the anti-coincidence circuit to lower further the background counting rates. There is also lead to improve shielding, including lead sheeting surrounding the high-precision counters. The background count rate of each of these three counters is somewhat different, apparently dependent on the location within the shield. The average background count rates of the counters are ca $4.5,3.6$, and $4.9 \mathrm{cpm}$. The corrected modern (1950) count rates based on analyses of both batches of NBS oxalic acid range from 44.5 to $45.0 \mathrm{cpm}$. The counting characteristics of the counters are so similar that a single main high voltage supply is used for all three, with additional biases of up to 100 volts adjustable separately for each counter to attain constant ratios of meson events in the two energy channels, to compensate for small variations in gas purity.

In practice, with tree-ring samples from ca $8000 \mathrm{yr} \mathrm{BP}$, most of the samples analyzed to high precision are measured for 9 to 15 days, in periods of 3 days at a time in each counter, all samples counted for at least one such period in each of the 3 counters. The counting sequence generally consists of 3-day countings of 2 samples, then a background, 2 more samples, and then a standard. Data from all gas counters are recorded on computer diskette every 20 minutes. In the daily data reduction, a Chauvenet rejection procedure is used to delete any 20-minute interval of any counter's data which has a probability of occurring naturally of $<1 / 2 \mathrm{~N}$, where $\mathrm{N}$ is the number of intervals; typically, any one counter has an interval rejected only once every 2 to 3 days.

The background to be applied to any 1-day counting of a sample or standard is calculated as follows: a linear regression of background count rate vs guard count rate is performed using the data collected from 3 months before through 3 months after the sample or standard count. A background value is applied based on the guard count rate on the day of sample analysis.

Several preparations of (old) oxalic acid-I and (new) oxalic acid-II have been used for determining the standard value for each counter. Again, for each day's sample counting, the mean of standards measured during the three months before and after the sample counting is applied.

Finally, 3 months after the sample counting, a final weighted average mean of the single-day results is calculated. The Chauvenet rejection procedure is applied to the single measurements for each sample.

CONFIRMATION OF HIGH-PRECISION CAPABILITY OF COUNTERS

In order to prove that the $2.5 \mathrm{~L}$ counters, filled to ca $3 \mathrm{~atm}$, would produce data of high precision and accuracy, we performed a test. We wished to obtain uncertainties in $\Delta^{14} \mathrm{C}$ of ca $2 \%$ for relatively modern material and ca $3 \%$ for the 6554 to 5350 BC samples we planned to measure in this project. Seven samples of bristlecone pine ranging through the Spörer minimum period were provided by one of us (CWF). The ${ }^{14} \mathrm{C}$ data from analysis of these samples were compared with those of Stuiver and Quay (1980). The data comparison is presented as Figure 1. As can readily be seen, the agreement of the Arizona and Seattle data is excellent, giving us confidence in the capability of these detectors.

EXTENSION OF THE BRISTLECONE PINE CHRONOLOGY TO $6554 \mathrm{BC}$

Six years ago, CWF collected a specimen of bristlecone pine that could be cross-dated to his existing chronology; this specimen of wood provided decadal samples ( $\mathrm{min} 40 \mathrm{~g}$ ) from the range 6554 to $6084 \mathrm{BC}$ (4 yr older than original assignment due to finding of "missing rings" in the 6084 to 5820 $\mathrm{BC}$ range). CWF was also able to provide decadal samples from another specimen covering the range 5820 to $5350 \mathrm{BC}$. Several years ago, CWF had provided both the Arizona and La Jolla radiocarbon labs with some samples from the period in the gap 6080 to $5820 \mathrm{BC}$, but the precision of the measurement of these samples was not high $( \pm 5$ to $8 \%$ ), the internal scatter of each lab's data was excessive, and the data from the two labs were in poor agreement. Unfortunately, there was insufficient wood remaining from that period to re-measure in this project and we have chosen not to use the lower precision data just to fill the gap.

RADIOCARBON RESULTS FOR WOOD FROM 6554 TO 5350 BC

It has taken us over two years to complete the measurement of the 106 samples ultimately provided to us. A while after the testing of the then new high-precision counters, gas purity problems arose, so that four of the samples were unmeasurable. The results of our analyses of the remaining 102 samples are given in Table 1 . The $\delta^{13} \mathrm{C}$ values are in $\%$, relative to the PDB standard. The ${ }^{14} \mathrm{C}$ ages are in years $\mathrm{BP}$, calculated with the conventional $5568-y{ }^{14} \mathrm{C}$ half-life. The decay correction used to calculate the $\Delta^{14} \mathrm{C}$ values is based on the $5730-\mathrm{yr}^{14} \mathrm{C}$ half-life, as is conventional for this purpose. The uncertainties of the ${ }^{14} \mathrm{C}$ measurements are the one standard deviation errors of the weighted means, choosing the larger of the error based purely on counting statistical grounds and that based on the standard deviation of the single-day data. In 5 cases, the ${ }^{14} \mathrm{C}$ results originally obtained were checked by analyzing duplicate samples from these decades; in 2 cases, the previous data were confirmed, while in the other 3 (for which the original data agreed poorly with that from surrounding decades) the data from the new samples were much more in line with those from the surrounding decades. We have chosen, on statistical grounds, to delete those 3 results from further use; we have no explanation for these deviant data.

We have plotted the data in various formats for examination and use in different ways. Figure 2 is a plot of $\Delta^{14} \mathrm{C}$ vs time (dendro-year $\mathrm{BC}$ ). The plot of data from this period looks much the same as from other periods of time. As a general trend, ${ }^{14} \mathrm{C}$ levels increase with more recent times, especially in the most modern centuries shown in Figure 2; this agrees with previous measurements and the trend of an 11,300-yr sinusoidal curve (Bruns et al, 1983). There are some clear wiggles in the curve: maxima are apparent at ca $6410,6360,5720,5610$, and 5460 BC. Minima are at ca 6480, 6250, 5750, and $5665 \mathrm{BC}$.

The data points are presented as ${ }^{14} \mathrm{C}$ age in years BP $v s$ true calendar year (dendro-year cal $\mathrm{BC}$ ) in Figure 3 for the 6554 to $5350 \mathrm{BC}$ range. The 
same features observable in Figure 2 are present in this plot, but may be less clear because of the scale. For usc in calibration of ${ }^{14} \mathrm{C}$ ages $\mathrm{BP}$, plots similar to those given as Figure 3 of Stuiver (1982) are presented here as Figure 4 , using only Arizona high-precision data. Figure 4A covers the dendro-year range of data from 6600 to $5900 \mathrm{cal} \mathrm{BC}$. Figure $4 \mathrm{~B}$ covers 6100 to $5400 \mathrm{cal}$ $\mathrm{BC}$, and Figure $4 \mathrm{C}$ covers 5600 to $4900 \mathrm{cal} \mathrm{BC}$. These plots give $1 \sigma$ bands based on the individual data points, presented as ${ }^{14} \mathrm{C}$ age in years BP $v s$ dendro-year cal BC. At this time, the bristlecone pine chronology is the only tree-ring chronology that continues unbroken to $6554 \mathrm{BC}$, although there is only one gap apparently remaining in the German oak chronology (Becker, pers commun; Linick, Suess \& Becker, 1985), which would extend to ca $7200 \mathrm{BC}$ if this gap was filled in. A detailed examination of the entire treering ${ }^{14} \mathrm{C}$ record, with reference to the observable periodicities and their causes, was performed by Damon \& Linick (1986).

\section{ACKNOWLEDGMENTS}

We would like to thank Carlos Ratto for treatment, combustion, and purification of all samples discussed here. Our thanks go to Janet Schaller for dedicated attention to the gas proportional counters, changing samples, and calculating daily data. We thank Robin Sweeney for plotting daily data and determining whether counters and samples were behaving acceptably during the past year. We acknowledge Chris Radnell's work in assembling most of the sample preparation line. We thank James Abbott, Lisa Warneke, and Robert Butcher for preparing the figures. This work was supported by the State of Arizona and NSF grant EAR-8314067.
REFERENCES

Bruns, M, Rheim, M, Linick, T W and Suess, H E, 1983, The atmospheric ${ }^{14} \mathrm{C}$ level in the 7 th millennium BC, in Mook, W G and Waterbolk, $\mathrm{H}$ T, eds, ${ }^{14} \mathrm{C}$ and archaeology conf, Proc: PACT, Strasbourg, v 8, p $511-516$.

Damon, P E, Lerman, J C and Long, A, 1978, Temporal fluctuations of atmospheric ${ }^{14} \mathrm{C}$ : causal factors and implications: Ann Rev Earth Planetary Sci, v 6, p 457-494.

Damon, P E and Linick, T W, 1986, Geomagnetic-heliomagnetic modulation of atmospheric radiocarbon concentrations, in Stuiver, $M$ and Kra, RS, eds, Internatl ${ }^{14} \mathrm{C}$ conf, $12 \mathrm{t}$, Proc: Radiocarbon, $v 28$, no. 2A.

Damon, P E, Long, A and Grey, D C, 1966, Fluctuation of atmospheric ${ }^{14} \mathrm{C}$ during the last six millennia: Jour Geophys Research, v 71, p 1055-1063.

. time scale, in Rafter, T A and Grant-Taylor, T,

Klein, J, Lerman, J C, Damon, P E and Linick, T W, 1980, Radiocarbon concentrations in the atmosphere: 8000 -year record of variations in tree rings: first results of a USA workshop, in Stuiver, $\mathrm{M}$ and $\mathrm{Kra}$, R S, eds. Internatl ${ }^{14} \mathrm{C}$ conf, 10 th. Proc: Radiocarbon, v 22 , no. 3, 950-961.

Linick, T W, Suess, H E and Becker, B, 1985, La Jolla measurements of radiocarbon in south German oak tree-ring chronologies: Radiocarbon, v 27, no. 1, p 20-32.

Stuiver, M, 1982, A high-precision calibration of the AD radiocarbon time scale: Radiocarbon, v 24 , no. $1, \mathrm{p} 1-26$.

Stuiver, $\mathrm{M}$ and Quay, P D, 1980, Changes in atmospheric ${ }^{14} \mathrm{C}$ attributed to a variable sun: Science, $v 9$, p $1-20$.

Stuiver, M, Robinson, S W and Yang, I C, $1979,{ }^{14} \mathrm{C}$ dating to 60,000 years BP with proportional counters, in Berger, $\mathrm{R}$ and Suess, $\mathrm{H}$ E, eds, Radiocarbon dating, Internat ${ }^{14} \mathrm{C}$ conf, 9th, Proc: Berkeley, Univ California Press, p 202-215.

Suess, H E, 1970, Bristlecone pine calibration of the radiocarbon time-scale $5200 \mathrm{BC}$ to the present, in Olsson, I U, ed, Nobel symposium, 12th, Radiocarbon variations and absolute chronology: New York, John Wiley \& Sons, p 303-311.

1978, La Jolla measurements of radiocarbon in tree-ring dated wood: Radiocarbon, v 20, no. 1, p 1-18.

1980, The radiocarbon record in tree rings of the last 8000 years, in Stuiver, $M$ 


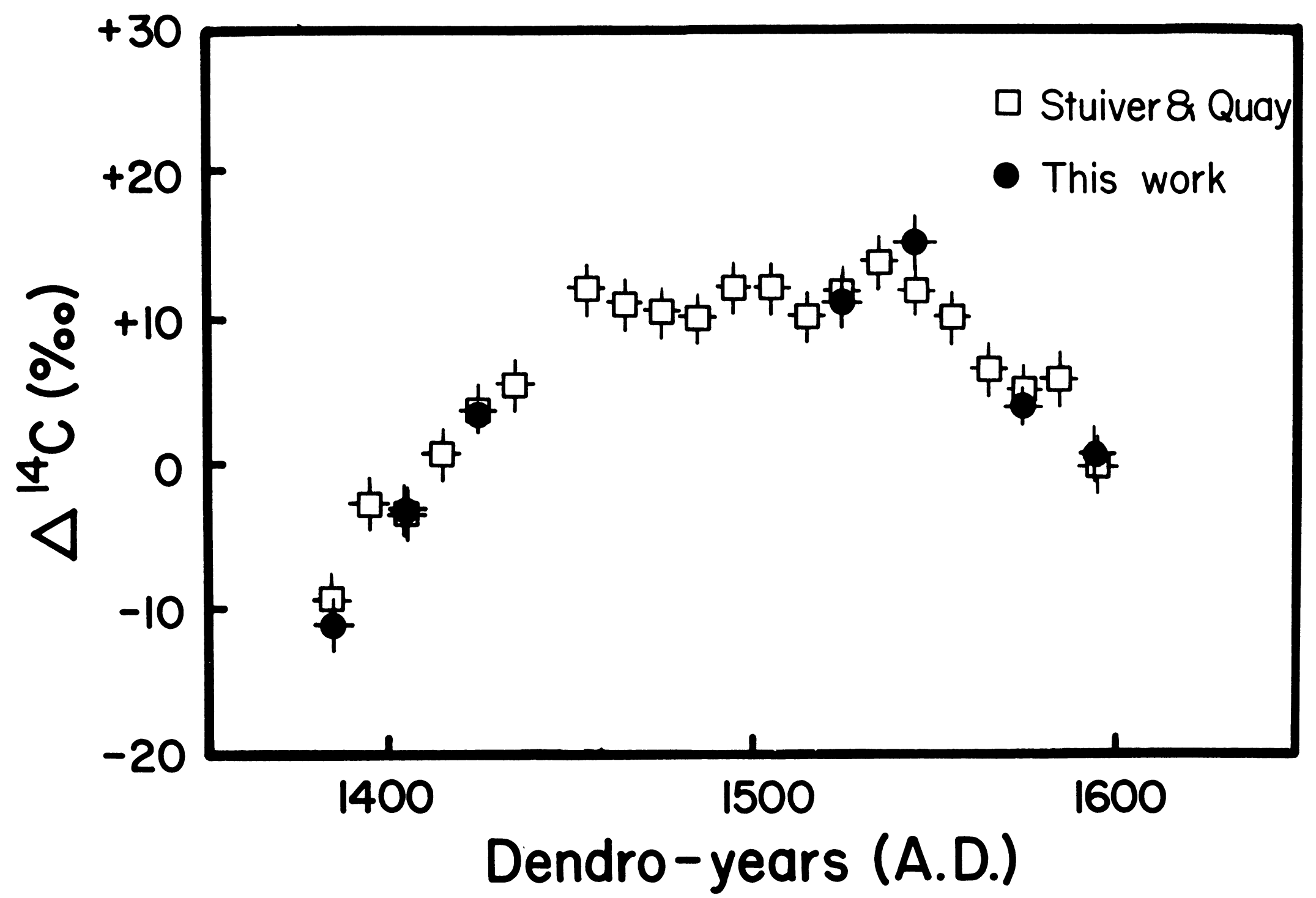

Fig 1. Comparison of Arizona and Seattle (Stuiver \& Quay, 1980) measurements of $\Delta^{14} \mathrm{C}$ vs time during the Spörer minimum 


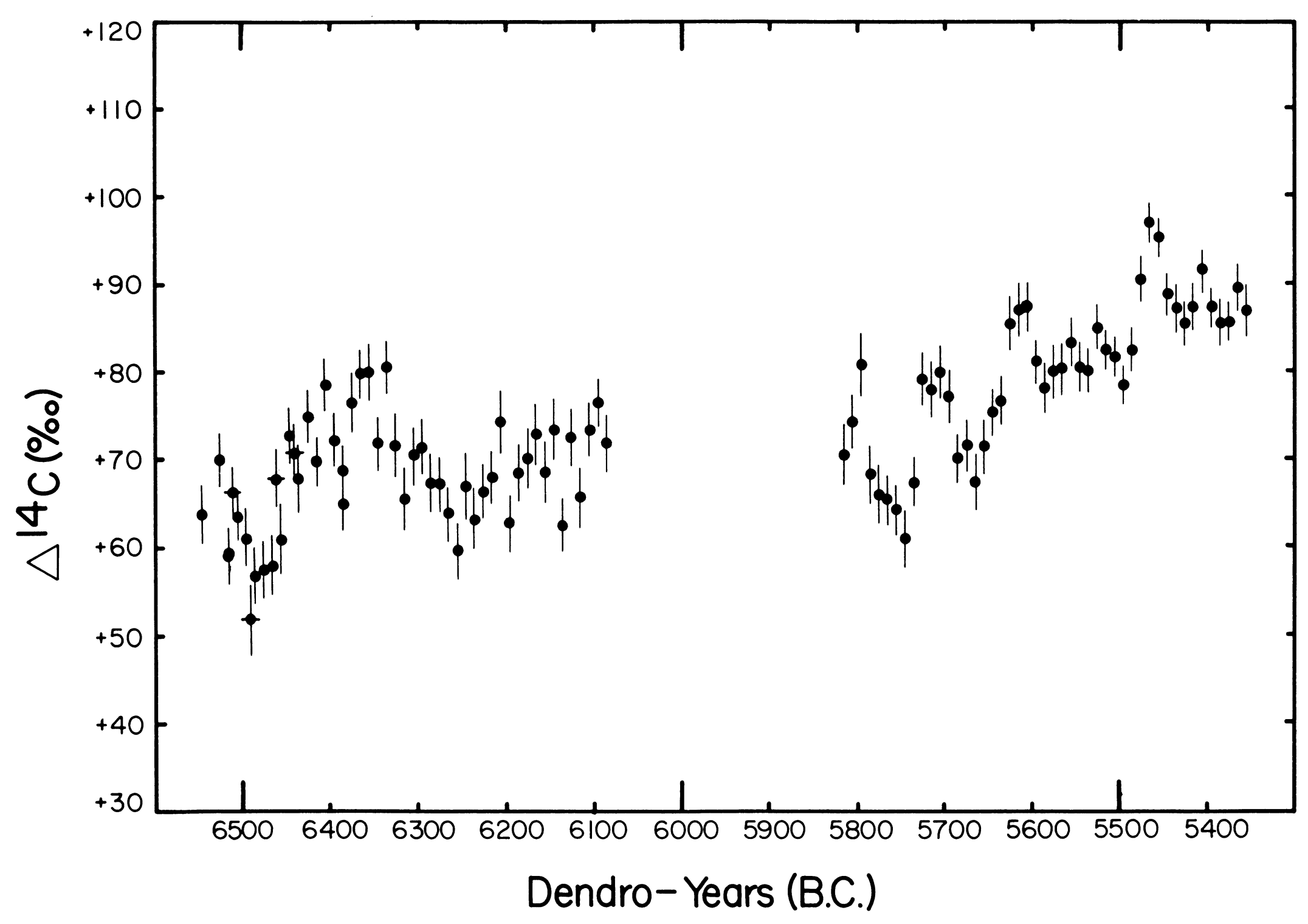

Fig 2. Temporal variation of $\Delta^{14} \mathrm{C}$ for the time ranges 6554 to $6084 \mathrm{BC}$ and 5820 to $5350 \mathrm{BC}$, based on high-precision Arizona measurements of decadal bristlecone pine samples 
Radiocarbon age (YEARS B.P.)

岗

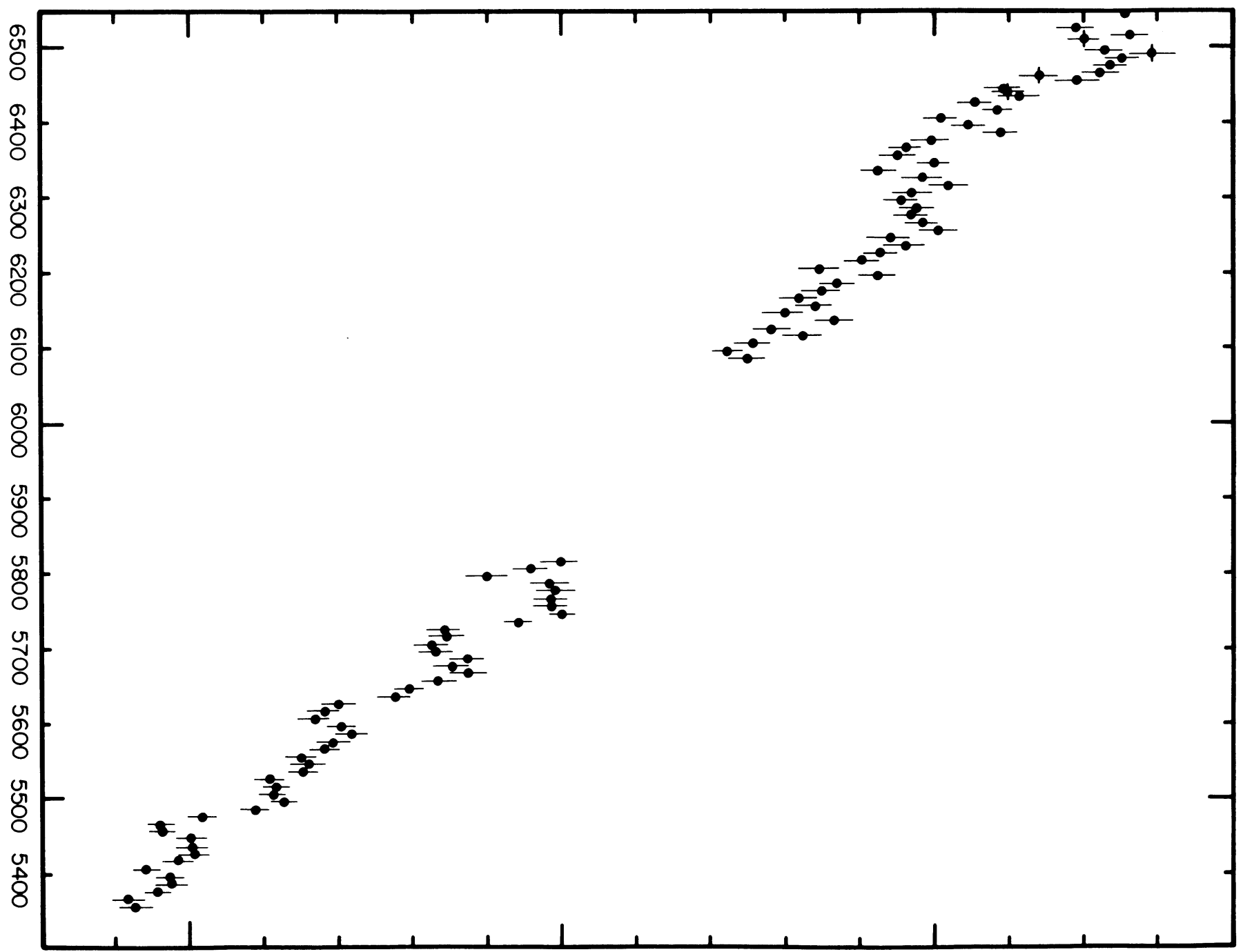




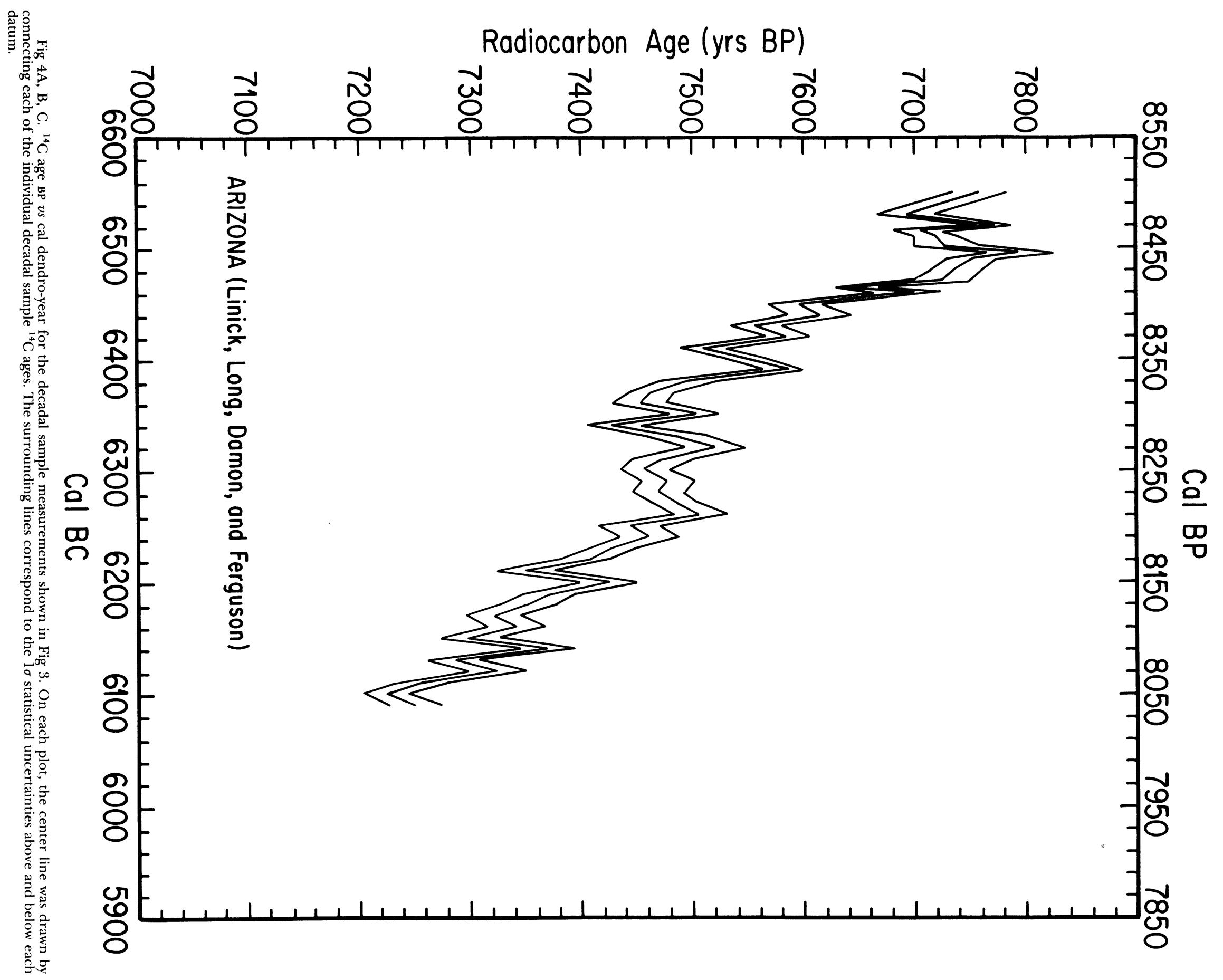




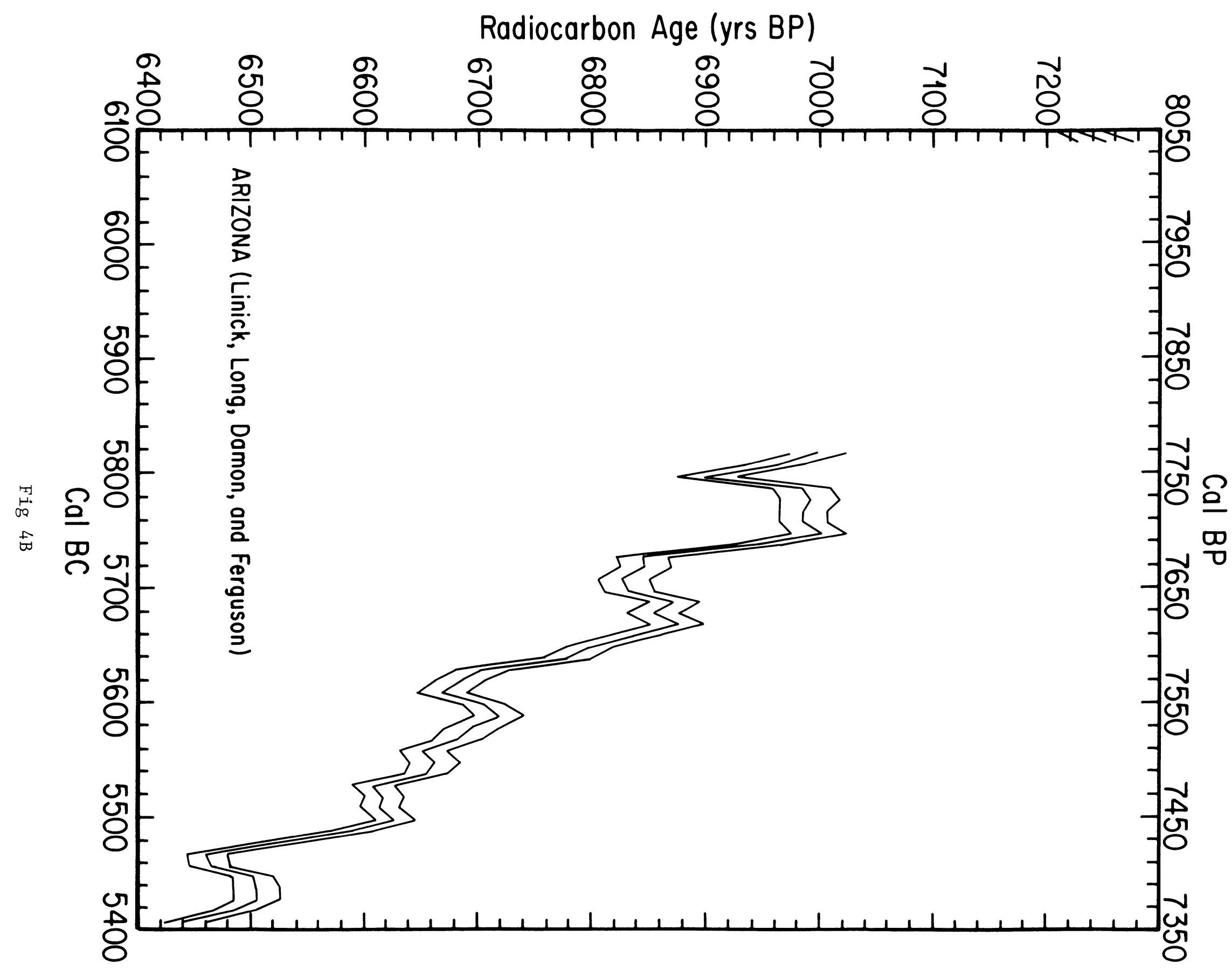


Radiocarbon Age (yrs BP)

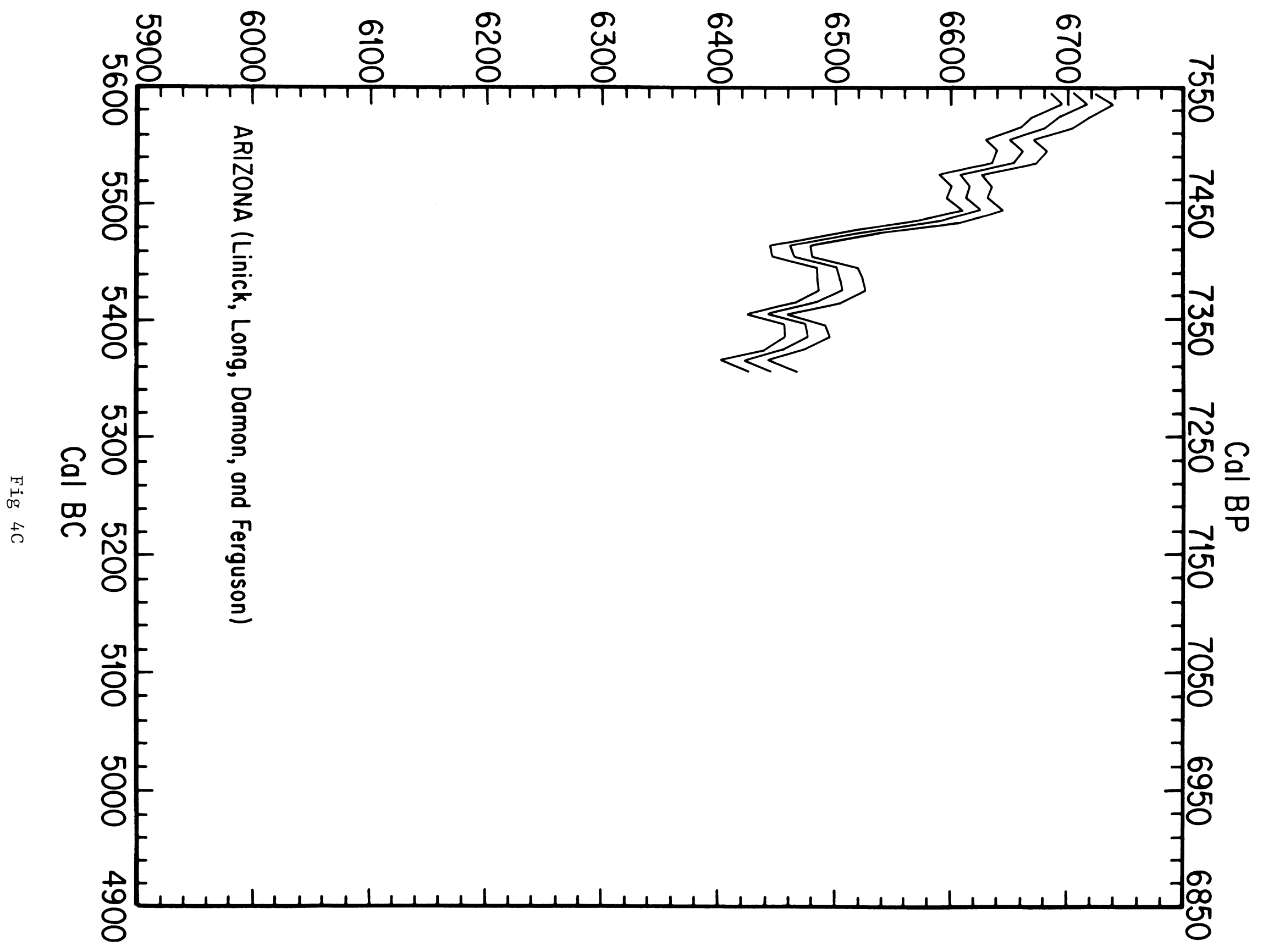


TABLE 1

Radiocarbon results for decadal bristlecone pine tree rings, 6554 to $5350 \mathrm{BC}$

\begin{tabular}{lllll}
\hline Lab No. & Mid-Point Dendro-Year & $\delta^{13} \mathrm{C}(\% \circ)$ & ${ }^{14} \mathrm{C}$ Age $(\mathrm{yr} \mathrm{BP})$ & $\Delta^{14} \mathrm{C}(\%)$ \\
\hline A-3926 & -6549 & -19.8 & $7758 \pm 24$ & $64.3 \pm 3.2$ \\
A-3928 & -6529 & -20.0 & $7691 \pm 24$ & $70.6 \pm 3.1$ \\
A-3929 & -6519 & -20.0 & $7763 \pm 25$ & $59.8 \pm 3.2$ \\
A-4204 & -6519 & -20.2 & $7782 \pm 22$ & $57.3 \pm 2.9$ \\
A-2341 & $-6514^{*}$ & -20.4 & $7704 \pm 23$ & $66.9 \pm 3.0$ \\
A-3930 & -6509 & -20.4 & $7720 \pm 20$ & $64.1 \pm 2.7$ \\
A-3796 & -6499 & -21.8 & $7729 \pm 29$ & $61.7 \pm 3.3$ \\
A-2342 & $-6494^{*}$ & -20.5 & $7794 \pm 31$ & $52.5 \pm 4.0$ \\
A-3797 & -6489 & -19.9 & $7753 \pm 23$ & $57.3 \pm 3.0$ \\
A-3798 & -6479 & -19.6 & $7737 \pm 23$ & $58.1 \pm 3.1$ \\
A-3799 & -6469 & -19.8 & $7724 \pm 25$ & $58.5 \pm 3.3$ \\
A-2343 & $-6464^{*}$ & -20.4 & $7643 \pm 25$ & $68.5 \pm 3.3$ \\
A-2862 & -6459 & -20.3 & $7694 \pm 30$ & $61.5 \pm 4.0$ \\
A-3800 & -6449 & -19.7 & $7593 \pm 24$ & $73.3 \pm 3.2$ \\
A-2344 & $-6444^{*}$ & -20.4 & $7602 \pm 24$ & $71.4 \pm 3.2$ \\
A-2863 & -6439 & -20.2 & $7615 \pm 29$ & $68.5 \pm 3.9$ \\
A-3801 & -6429 & -19.1 & $7557 \pm 22$ & $75.5 \pm 3.0$ \\
A-3995 & -6419 & -20.0 & $7586 \pm 20$ & $70.3 \pm 2.7$ \\
A-3883 & -6409 & -20.0 & $7510 \pm 22$ & $79.2 \pm 3.0$ \\
A-3884 & -6399 & -19.8 & $7547 \pm 23$ & $72.9 \pm 3.0$ \\
A-2521 & -6389 & -19.8 & $7592 \pm 23$ & $65.6 \pm 3.0$ \\
A-4205 & -6389 & -19.6 & $7578 \pm 21$ & $67.8 \pm 2.8$ \\
A-3885 & -6379 & -20.0 & $7496 \pm 25$ & $77.2 \pm 3.4$ \\
A-3886 & -6369 & -20.4 & $7463 \pm 21$ & $80.3 \pm 2.8$ \\
A-2525** & -6359 & -19.8 & $7338 \pm 27$ & $95.9 \pm 3.7$ \\
A-3887 & -6359 & -20.2 & $7452 \pm 24$ & $80.5 \pm 3.3$ \\
A-2526 & -6349 & -20.0 & $7502 \pm 22$ & $72.4 \pm 3.0$ \\
A-2527 & -6339 & -20.1 & $7427 \pm 24$ & $81.2 \pm 3.0$ \\
A-2528 & -6329 & -20.4 & $7485 \pm 27$ & $72.2 \pm 3.6$ \\
A-2529 & -6319 & $7521 \pm 27$ & $66.1 \pm 3.6$ \\
A-2530 & -6309 & $7472 \pm 27$ & $71.2 \pm 3.6$
\end{tabular}

TABLE 1 (continued)

\begin{tabular}{|c|c|c|c|c|}
\hline Lab No. & Mid-Point Dendro-Year & $\delta^{13} \mathrm{C}(\% \circ)$ & ${ }^{14} \mathrm{C}$ Age (yr BP) & $\Delta^{14} \mathrm{C}(\% \circ)$ \\
\hline$A-2540$ & -6299 & -20.0 & $7457 \pm 23$ & $72.0 \pm 3.1$ \\
\hline A-2541 & -6289 & -20.1 & $7478 \pm 24$ & $67.9 \pm 3.2$ \\
\hline A-2542 & -6279 & -19.7 & $7469 \pm 23$ & $67.8 \pm 3.1$ \\
\hline $\mathrm{A}-2543^{\star \star}$ & -6269 & -20.4 & $7563 \pm 21$ & $54.1 \pm 2.8$ \\
\hline$A-4028$ & -6269 & -20.7 & $7485 \pm 22$ & $64.4 \pm 3.0$ \\
\hline A-2544 & -6259 & -20.4 & $7507 \pm 25$ & $60.2 \pm 3.2$ \\
\hline$A-2556$ & -6249 & -20.2 & $7441 \pm 29$ & $67.6 \pm 3.8$ \\
\hline A-2557 & -6239 & -19.9 & $7461 \pm 27$ & $63.7 \pm 3.6$ \\
\hline$A-2558$ & -6229 & -20.6 & $7428 \pm 22$ & $66.9 \pm 3.0$ \\
\hline A-2559 & -6219 & -20.4 & $7404 \pm 23$ & $68.6 \pm 3.1$ \\
\hline$A-2560$ & -6209 & -20.5 & $7348 \pm 27$ & $74.9 \pm 3.6$ \\
\hline A-3214 & -6199 & -20.3 & $7425 \pm 25$ & $63.3 \pm 3.3$ \\
\hline$A-3215^{\star \star}$ & -6189 & -20.9 & $7501 \pm 23$ & $52.0 \pm 3.0$ \\
\hline A-3895 & -6189 & -20.3 & $7372 \pm 24$ & $69.1 \pm 3.2$ \\
\hline$A-3216$ & -6179 & -19.7 & $7350 \pm 26$ & $70.7 \pm 3.5$ \\
\hline$A-3217$ & -6169 & -20.2 & $7320 \pm 25$ & $73.4 \pm 3.4$ \\
\hline$A-3218$ & -6159 & -19.9 & $7342 \pm 26$ & $69.2 \pm 3.5$ \\
\hline A-3223 & -6149 & -20.1 & $7298 \pm 26$ & $73.9 \pm 3.5$ \\
\hline A-3224 & -6139 & -20.1 & $7368 \pm 25$ & $63.1 \pm 3.2$ \\
\hline A-3225 & -6129 & -20.0 & $7284 \pm 25$ & $73.0 \pm 3.4$ \\
\hline$A-3226$ & -6119 & -19.7 & $7324 \pm 26$ & $66.3 \pm 3.4$ \\
\hline A-3227 & -6109 & -19.5 & $7258 \pm 23$ & $74.0 \pm 3.1$ \\
\hline A-3228 & -6099 & -20.2 & $7224 \pm 20$ & $77.1 \pm 2.7$ \\
\hline A-3229 & -6089 & -20.2 & $7250 \pm 24$ & $72.4 \pm 3.2$ \\
\hline$A-3009$ & -5815 & -20.8 & $6998 \pm 25$ & $70.5 \pm 3.4$ \\
\hline A-2734 & -5805 & -20.6 & $6959 \pm 22$ & $74.4 \pm 3.0$ \\
\hline$A-2735$ & -5795 & -20.4 & $6901 \pm 27$ & $80.8 \pm 3.6$ \\
\hline$A-2736$ & -5785 & -20.6 & $6985 \pm 26$ & $68.3 \pm 3.4$ \\
\hline$A-2737$ & -5775 & -20.9 & $6992 \pm 26$ & $66.1 \pm 3.4$ \\
\hline$A-2738$ & -5765 & -20.9 & $6987 \pm 21$ & $65.4 \pm 2.8$ \\
\hline$A-2739$ & -5755 & -20.4 & $6986 \pm 22$ & $64.3 \pm 2.9$ \\
\hline A-2740 & -5745 & -20.6 & $7001 \pm 24$ & $61.0 \pm 3.2$ \\
\hline
\end{tabular}


TABLE 1 (continued)

\begin{tabular}{|c|c|c|c|c|}
\hline Lab No. & Mid-Point Dendro-Year & $\delta^{13} \mathrm{C}(\% \circ)$ & ${ }^{14} \mathrm{C}$ Age (yr BP) & $\Delta^{14} \mathrm{C}(\% \circ)$ \\
\hline$A-2741$ & -5735 & -20.3 & $6943 \pm 21$ & $67.4 \pm 2.8$ \\
\hline A-2742 & -5725 & -20.0 & $6844 \pm 23$ & $79.3 \pm 3.2$ \\
\hline$A-2743$ & -5715 & -20.2 & $6847 \pm 23$ & $77.8 \pm 3.2$ \\
\hline$A-2749$ & -5705 & -20.2 & $6827 \pm 23$ & $79.8 \pm 3.1$ \\
\hline$A-2750$ & -5695 & -20.2 & $683 ? \pm 22$ & $77.1 \pm 3.0$ \\
\hline$A-2751$ & -5685 & -19.6 & $6874 \pm 22$ & $70.1 \pm 2.9$ \\
\hline$A-3018$ & -5675 & -20.0 & $6853 \pm 23$ & $71.6 \pm 3.1$ \\
\hline A-3019 & -5665 & -20.1 & $6876 \pm 24$ & $67.4 \pm 3.2$ \\
\hline$A-3020$ & -5655 & -19.8 & $6836 \pm 24$ & $71.4 \pm 3.2$ \\
\hline$A-3021$ & -5645 & -19.8 & $6797 \pm 20$ & $75.3 \pm 2.7$ \\
\hline$A-2752$ & -5635 & -20.2 & $6777 \pm 21$ & $76.7 \pm 2.8$ \\
\hline$A-2753$ & -5625 & -20.2 & $6702 \pm 23$ & $85.5 \pm 3.1$ \\
\hline$A-2754$ & -5615 & -19.6 & $6682 \pm 22$ & $86.9 \pm 2.9$ \\
\hline$A-2755$ & -5605 & -18.8 & $6668 \pm 22$ & $87.3 \pm 2.9$ \\
\hline$A-3036$ & -5595 & -19.5 & $6705 \pm 19$ & $81.2 \pm 2.5$ \\
\hline A-3037 & -5585 & -20.1 & $6718 \pm 22$ & $78.1 \pm 2.9$ \\
\hline$A-3038$ & -5575 & -20.4 & $6694 \pm 24$ & $80.0 \pm 3.2$ \\
\hline A-3039 & -5565 & -21.6 & $6682 \pm 22$ & $80.3 \pm 3.0$ \\
\hline$A-3040$ & -5555 & -20.2 & $6650 \pm 21$ & $83.3 \pm 2.8$ \\
\hline$A-3041$ & -5545 & -19.5 & $6661 \pm 22$ & $80.5 \pm 2.9$ \\
\hline A-3042 & -5535 & -20.5 & $6654 \pm 19$ & $80.1 \pm 2.6$ \\
\hline$A-3043$ & -5525 & -20.3 & $6608 \pm 19$ & $85.0 \pm 2.5$ \\
\hline$A-3066$ & -5515 & -20.4 & $6617 \pm 17$ & $82.5 \pm 2.3$ \\
\hline A-3067 & -5505 & $-20 \cdot 2$ & $6613 \pm 17$ & $81.7 \pm 2.3$ \\
\hline A-3068 & -5495 & -20.1 & $6627 \pm 17$ & $78.5 \pm 2.3$ \\
\hline A-3069 & -5485 & -20.0 & $6588 \pm 19$ & $82.4 \pm 2.5$ \\
\hline A-3053 & -5475 & -20.6 & $6518 \pm 19$ & $90.6 \pm 2.6$ \\
\hline A-3054 & -5465 & -20.4 & $6461 \pm 17$ & $97.0 \pm 2.3$ \\
\hline$A-3055$ & -5455 & -19.8 & $6464 \neq 17$ & $95.3 \pm 2.3$ \\
\hline$A-3056$ & -5445 & -20.5 & $6502 \pm 18$ & $88.8 \pm 2.5$ \\
\hline A-3057 & -5435 & -20.6 & $6504 \pm 20$ & $87.2 \pm 2.7$ \\
\hline$A-3058$ & -5425 & -20.7 & $6506 \pm 19$ & $85.5 \pm 2.5$ \\
\hline A-3059 & -5415 & -20.8 & $6484 \pm 19$ & $87.3 \pm 2.6$ \\
\hline
\end{tabular}

TABLE 1 (continued)

\begin{tabular}{lllll}
\hline Lab No. & Mid-Point Dendro-Year & $\delta^{13} \mathrm{C}(\%)$ & ${ }^{14} \mathrm{C}$ Age $(\mathrm{yr} B P)$ & $\Delta^{14} \mathrm{C}(\% \circ)$ \\
\hline A-3060 & -5405 & -20.7 & $6442 \pm 18$ & $91.6 \pm 2.5$ \\
A-3072 & -5395 & -20.5 & $6475 \pm 17$ & $87.3 \pm 2.3$ \\
A-3073 & -5385 & -20.6 & $6477 \pm 19$ & $85.6 \pm 2.6$ \\
A-3074 & -5375 & -20.2 & $6457 \pm 17$ & $85.7 \pm 2.2$ \\
A-3075 & -5365 & -20.1 & $6421 \pm 21$ & $88.9 \pm 2.8$ \\
A-3076 & -5355 & -20.2 & $6447 \pm 21$ & $84.4 \pm 2.9$
\end{tabular}

* 20-year sample

** ${ }^{14} \mathrm{C}$ data for sample rejected after measurement of second sample from same decade 